\title{
Smartphone addiction and its impact on musculoskeletal pain in neck, shoulder, elbow, and hand among college going students: a cross-sectional study
}

\author{
Sohel Ahmed ${ }^{1^{*}}\left(\mathbb{D}\right.$, Arushi Mishra ${ }^{2}$, Rahemun Akter ${ }^{1}$, Md. Hasanuzzaman Shah ${ }^{3}$ and Asima Akter Sadia ${ }^{4}$
}

\begin{abstract}
Introduction: Prolonged physical exposure during smartphone usage results in poor posture causing pain in neck, shoulder, elbow, and hands. So, our aim was to investigate the effect of smartphone addiction on musculoskeletal pain.

Methods: This cross-sectional study was carried out by a random sampling method from recognized institute in Bangladesh and India. Three hundred twenty-six participants, including male and female, aged between 18 and 30 years participated in this study. Candidates were requested to fill-up a performa containing demographics, Smartphone addiction scale-short form (SAS-SF), Shoulder pain and disability index (SPADI), Neck disability index (NDI), Oxford elbow score (OEC), and Cornell Hand Discomfort Questionnaire (CHDQ).

Results: The mean age were $22.58 \pm 3.19$ years, weight $60 \pm 11.30 \mathrm{~kg}$, height $162.83 \pm 9.74 \mathrm{~cm}$, and body mass index (BMI) of the participants were $22.69 \pm 4.36 \mathrm{~kg} / \mathrm{m}^{2} .43 .3 \%$ participants reported neck pain, $42.9 \%$ shoulder pain, and $27.9 \%$ reported pain on their elbow while prolonged smartphone use. There was major difference in NDI $(p=$ 0.047), SPDI $(p=0.005)$, OES ( $p=0.002)$, and CHDQ $(p=<0.001)$ among Bangladeshi and Indian population. The SAS has a significant association with NDI; $p<0.001$, SPDI; $p<0.001$, OES; $p<0.001$, and CHDQ; $p<0.001$.

Conclusion: Smartphone addiction negatively impacted and positively related with the musculoskeletal pain in neck, shoulder, elbow, and hand. Care should be given towards the proper use of smartphone and increase public awareness regarding the negative consequences of this serious issue.
\end{abstract}

Keywords: Addiction, Cross-sectional study, Musculoskeletal pain, Pain, Smartphone

\section{Introduction}

The smartphone is one of the most popular and essential gadget among youngsters of today. Compact high resolution cameras, easy and fast access to email/messages, GPS navigation apps, state of the art media players, easy access to the internet, social media, and mobile gaming

\footnotetext{
*Correspondence: ptsohel@gmail.com

${ }^{1}$ Mount Adora Physiotherapy \& Neurorehabilitation, Center, Mount Adora Hospital, Akhalia-3100, Sylhet, Bangladesh

Full list of author information is available at the end of the article
}

are all reasons that contribute to the numerous use and obsession to smartphone. Due to the increase in smartphone usage, there has been an increase in potential risks of musculoskeletal pain [1]. The latest findings from a recent study in the USA reported that, $46 \%$ smartphone users believe that their phone is something "they cannot live without" [2]. In the meantime, there has been a significant increase in the use of smartphone from the year 2011 to 2014 by $35 \%$ to $64 \%$ in the USA [2].

While using a Smartphone it is required for the user to maintain their head in prolonged downward 
position and hold their device in front of them to read the screen, which makes the head tilt forward causing the flattening of the cervical lordotic curve. Forward head posture can lead to the onset of neck and back pain syndromes [1]. During this activity, the user is fixed in one position for a prolonged time without any movement leading to the development of fatigueness of muscles and causes various musculoskeletal disorders [3]. It has also been found that mobile phone addiction has also been associated with subsequent stress, sleep complications, behavioral changes, mood swings, and even depression. Students are more dependent on smartphones and are potentially more vulnerable to smartphone addiction as compared to the older generation [4]. A recent study in India reported that as a cause of prolonged smartphone use, $46.9 \%$ of students have pain in their neck and $29.2 \%$ in their thumb [5]. In another study $66.4 \%$ participants were addicted to their smartphone and $19.1 \%$ having positive Finkelsteine's test [6]. Another study reported that $79 \%$ of the participants aged between 18 and 44 years use their smartphone almost throughout the day, leaving only $2 \mathrm{~h}$ of their entire day spent without their smartphone in hand. The smartphone addiction is also termed as non-chemical addiction or so called technological addiction [7].

Although, various studies have done on smartphone addiction are mostly focused on mental health [8], stress [2], satisfaction with life, loneliness [9], and academic performances [10]. Few studies have also examined the influence of smartphone addiction on musculoskeletal symptoms. Mustafaoglu R et al. reported that pain in the dorsum, neck, wrist, and hand is highly prevalent among the smartphone addicted population [3]. S. Ahmed et al. reported smartphone addiction is associated with neck pain and thumb pain among college students [5]; in another study, about $82.38 \%$ population stated that they have discomfort in various parts of their body due to prolonged smartphone use [11]. It is require to evaluate the impact of smartphone use on musculoskeletal health especially among the vulnerable group of college going students. To date, best of our knowledge, there is no comprehensive study which evaluates the impact of smartphone addiction on musculoskeletal pain in the neck, shoulder, elbow, and hand together with different scales. This cross-sectional study also evaluates whether there are any differences between smartphone addiction and pain among Bangladeshi and Indian population. We hypothesized that there will be significant difference in the level of smartphone addiction and musculoskeletal pain among the participants among two countries.

\section{Methods}

\section{Ethical statement}

This cross-sectional study was done in accordance with the declaration laid by, declaration of Helsinki (revised 2013) for recruiting human subject and Bangladesh medical research council guideline 2014. Ethical permission was obtained from the institutional ethical review board of Mount Adora Hospital (MAH/ERB: 02/2020) and departmental ethical review board of Maharishi Markandeshwar university, (IEC-1215) Solan, Himachal Pradesh, India. A digital consent was obtained from each participant after brief description of the purpose of the study putting a separate section in the form by asking a question "do you agree to undergo in this study?" The design of the study, data collection procedure, presentation of the data, and citation comply with the standard Committee on publication Ethics (COPE) guideline.

\section{Subject and procedure}

A cross-sectional study was done among physiotherapy students in Bangladesh and India between the 20th January 2020 and the 25th February 2020. Simple random sampling method was used to recruit the required sample. Study sampling population was recruited by listing the students of two different universities in Bangladesh and India from the department of physiotherapy. A random sampling technique was used by using computergenerated random number generator from the sample population of 665 students to make a sampling frame of 326 students identifying according to the pre-fixed inclusion and exclusion criteria from the recognized university.

\section{Subject recruitment criteria}

This cross-sectional study comprised of both male and female participants. The required subject selection criteria included candidates age group between 18 and 30 years, who were able to understand the English language to fill up the questionnaire and willing to give consent to participate in this study. The exclusion criteria were any known condition which could lead to pain in the neck or upper limb, recent fracture in neck and upper limb, any traumatic injury to neck and upper limb prior 6 months, congenital abnormalities and severe surgical and neurological disorders.

\section{Sample size estimation}

The subjects size was calculated by utilizing the formula for estimating proportion: $n=Z \alpha^{2} P(1-P) / d 2$, where $Z \alpha=1.96 ; P=75.8 \%$; from the previous published article [12], and $d=5 \%$. The study required a minimum of 
326 participants. We did not expect $10 \%$ incomplete form as we have set the option required in every question in Google forms.

\section{Survey development Demographic variables}

Demographic characteristics such as gender, age, weight, height, body mass index (BMI), year of study, duration of owing a smartphone, daily smartphone usage time, purpose of smartphone use in a typical day such as text messaging, social networking, watching videos, and gaming were included.

\section{Smartphone addiction scale-short version (SAS-SV)}

The SAV-SV is a 6-point Likert type scale containing 10 questions. The scale starting from 1 (strongly disagree) to 6 (strongly agree). The overall score ranges from 10 to 60 . Higher score indicates high risk of smartphone addiction. The scale is valid and reliable to measure smartphone addiction. The internal consistency of SAS-SV was verified by Cronbach's alpha of 0.911 among adolescent population [13]

\section{Neck Disability Index (NDI)}

The NDI is a widely used valid and reliable instrument to measure neck pain. The questionnaire has involved a 10 -item Likert scale ranging from 0 (no pain) to 5 (worst pain). The total score ranges from 10 to 50 , where high score indicate severer neck disability. The intra class correlations value of NDI is in between 0.50 and 0.98 indicates good validity and reliability of the tools [14].

\section{Shoulder Pain and Disability Index (SPADI)}

The shoulder pain and disability index is used to measure shoulder pain and disability is a 13-item scale that have two domains; 5 items subscale measured pain and 8 item subscale measured disability on a numeric pain rating scale. The total score ranged from 0 to 140 was expressed as a percentage. The percentage score ranged from 0 to 100 , where a greater score represented more disability [15]. The test-retest reliability of SPADI was ranged from 0.64 to 0.66 and internal consistency range from 0.8604 to 0.9507 [16].

\section{Oxford elbow score}

A 12-item questionnaire was reported to measure elbow pain and function. Each item responses were scored from 0 to 4 Likert scale. The total sum score of all items were used for analysis. The Cronbach's alpha 0.92 showing excellent reliability of this scale [17].

\section{Cornell Hand Discomfort Questionnaire (CHDQ)}

The CHDQ is a valid and reliable tool to measure pain in the hand. The questionnaire contains three domains including experience of pain, discomforts of pain, and interference of pain. The total discomfort score was calculated as frequency $\times$ discomfort $\times$ interference. The maximum score of one shaded area of one hand is 45 and total score of the six shaded area is 270 . We ask the participants to fill-up the questionnaire for only domain hand. The validity of the questionnaire was established by Erdinc et al. reported the Kappa coefficients, which is ranging from 0.56 to 0.97 indicated moderate to good test-retest reliability [18].

\section{Survey validation and administration}

The draft of the survey questionnaire was not subjected to content validation as the tool we used was an already validated tool. The final draft of the questionnaire was tested initially on five representative population to check the response time; it took no more than $20 \mathrm{~min}$ to complete the questionnaire. From the sample frame of 665 population, 326 potential participants were selected by simple random sampling method from two reputed Universities of Bangladesh and India. Face-to-face data collection was carried out during the break time of the students' college hour. We utilized Google Forms ${ }^{\circledR}$ platform to collect the survey response as it is echo friendly. The enrolled student's contact details was obtained and the survey link was send to the participant's either WhatsApp, Messenger, or text message through the smartphone. Google Forms prevents the incomplete submission by putting the option required in every question.

\section{Data analysis}

Data analysis was carried out by using SPSS 20.0 software for windows. The continuous variables are presented as mean and 95\% confidential interval. Categorical variables are presented as number and percentage. Between groups analysis was conducted by using Mann-Whitney $U$ test. Association between SAC and NDI, SPADI, OES, and CHDQ was measured by using chi-square test.

\section{Results}

A number of 326 participants participated in this crosssectional study. Among the participants, 167 were male and 159 were female. The mean age, weight, height, and body mass index (BMI) of the participants were 22.58 \pm 3.19 years, $60 \pm 11.30 \mathrm{~kg}, 162.83 \pm 9.74 \mathrm{~cm}$, and $22.69 \pm 4.36 \mathrm{~kg} / \mathrm{m}^{2}$, respectively. Among the participants, $69.2 \%$ were moderate to severely addict to their smartphones. The participants' demographic variables such as study year, owning smartphone time, duration 
Table 1 Demographic data of the study participants

\begin{tabular}{|c|c|c|c|c|c|}
\hline Variables & & Bangladeshi & Indian & Total & $P$ value \\
\hline \multirow[t]{2}{*}{ Gender } & Male & $126(68.1 \%)$ & $41(29.1 \%)$ & $167(51.2 \%)$ & $<.001$ \\
\hline & Female & $59(31.9 \%)$ & $100(70.9 \%)$ & $159(48.8 \%)$ & \\
\hline \multirow[t]{6}{*}{ Year of study } & 1st year & $17(9.2 \%)$ & $17(12.1 \%)$ & $34(10.4 \%)$ & 0.360 \\
\hline & 2nd year & 39 (21.1\%) & $20(14.2 \%)$ & $59(18.1 \%)$ & \\
\hline & 3rd year & $33(17.8 \%)$ & $28(19.9 \%)$ & $61(17.8 \%)$ & \\
\hline & 4th year & $12(6.5 \%)$ & $44(31.2 \%)$ & $56(17.2 \%)$ & \\
\hline & Intern & $52(28.1 \%)$ & $5(3.5 \%)$ & $57(17.5 \%)$ & \\
\hline & PG & $32(17.3 \%)$ & $27(19.1 \%)$ & $59(18.1 \%)$ & \\
\hline \multirow[t]{5}{*}{ Owning smartphone time } & 1 year & $15(8.1 \%)$ & $7(5.0 \%)$ & $22(6.7 \%)$ & 0.622 \\
\hline & $2-3$ years & $23(12.4 \%)$ & $26(18.4 \%)$ & $49(15.0 \%)$ & \\
\hline & $4-5$ years & $58(31.4 \%)$ & $41(29.1 \%)$ & $99(30.4 \%)$ & \\
\hline & $6-7$ years & $36(19.5 \%)$ & $33(23.4 \%)$ & $69(21.2 \%)$ & \\
\hline & $>7$ years & $53(28.6 \%)$ & $34(24.1 \%)$ & $87(26.7 \%)$ & \\
\hline \multirow[t]{5}{*}{ Duration of smartphone use per day } & $1 \mathrm{~h}$ & $12(6.5 \%)$ & $2(1.4 \%)$ & $14(4.3 \%)$ & 0.014 \\
\hline & $2-3 h$ & $44(23.8 \%)$ & $31(22.0 \%)$ & $75(23.0 \%)$ & \\
\hline & $4-5 \mathrm{~h}$ & $79(42.7 \%)$ & $49(34.8 \%)$ & $128(39.3 \%)$ & \\
\hline & $6-7 h$ & $29(15.7 \%)$ & $41(29.1 \%)$ & $70(21.5 \%)$ & \\
\hline & $>7 \mathrm{~h}$ & $21(11.4 \%)$ & $18(12.8 \%)$ & $39(12.0 \%)$ & \\
\hline \multirow[t]{5}{*}{ Time spent for social media per day } & $<1 \mathrm{~h}$ & $40(21.6 \%)$ & $21(14.9 \%)$ & $61(18.7 \%)$ & 0.185 \\
\hline & $1-2 \mathrm{~h}$ & $79(39.5 \%)$ & $58(41.1 \%)$ & $131(40.2 \%)$ & \\
\hline & $3-4 h$ & $48(25.9 \%)$ & $38(27.0 \%)$ & $86(26.4 \%)$ & \\
\hline & $5-6 h$ & $12(6.5 \%)$ & $21(14.9 \%)$ & $33(10.1 \%)$ & \\
\hline & $>6 \mathrm{~h}$ & $12(6.5 \%)$ & $3(2.1 \%)$ & $15(4.6 \%)$ & \\
\hline \multirow[t]{5}{*}{ Time spent for chatting with friends per day } & $<1 \mathrm{~h}$ & $101(54.6 \%)$ & $78(55.3 \%)$ & $179(54.9 \%)$ & 0.359 \\
\hline & $1-2 \mathrm{~h}$ & $51(27.6 \%)$ & $52(36.9 \%)$ & $103(31.6 \%)$ & \\
\hline & $3-4 h$ & $24(13.0 \%)$ & $9(6.4 \%)$ & $33010.1 \%$ & \\
\hline & $5-6 h$ & $5(2.7 \%)$ & $2(1.4 \%)$ & $7(2.1 \%)$ & \\
\hline & $>6 h$ & $4(2.2 \%)$ & $0(0 \%)$ & $4(1.2 \%)$ & \\
\hline \multirow[t]{5}{*}{ Time spent for watching YouTube videos per day } & $<1 \mathrm{~h}$ & $88(47.6 \%)$ & $70(49.6 \%)$ & $158(48.5 \%)$ & 0.489 \\
\hline & $1-2 \mathrm{~h}$ & $57(30.8 \%)$ & $48(34.0 \%)$ & $105(32.2 \%)$ & \\
\hline & $3-4 h$ & $33(17.8 \%)$ & $17(12.1 \%)$ & $50(15.3 \%)$ & \\
\hline & $5-6 h$ & $4(2.2 \%)$ & $4(2.8 \%)$ & $8(2.5 \%)$ & \\
\hline & $>6 \mathrm{~h}$ & $3(1.6 \%)$ & $2(1.4 \%)$ & $5(1.5 \%)$ & \\
\hline \multirow[t]{5}{*}{ Time spent for playing games per day } & $<1 \mathrm{~h}$ & $139(75.1 \%)$ & $111(78.7 \%)$ & $250(76.7 \%)$ & 0.465 \\
\hline & $1-2 \mathrm{~h}$ & $30(16.2 \%)$ & $19(13.5 \%)$ & $49(15.0 \%)$ & \\
\hline & $3-4 h$ & 13() $7.0 \%$ & $9(6.4 \%)$ & $22(6.7 \%)$ & \\
\hline & $5-6 h$ & $2(1.1 \%)$ & $1(.7 \%)$ & $3(.9 \%)$ & \\
\hline & $>6 \mathrm{~h}$ & $1(.5 \%)$ & $1(.7 \%)$ & $2(.6 \%)$ & \\
\hline \multirow[t]{4}{*}{ Smartphone addiction category } & No addiction & $8(4.3 \%)$ & $7(5.0 \%)$ & $15(4.6 \%)$ & $<0.001$ \\
\hline & Mild addiction & $49(26.5 \%)$ & $61(43.3 \%)$ & $110(33.7 \%)$ & \\
\hline & Moderate addiction & $93(50.3 \%)$ & $58(41.1 \%)$ & $151(46.3 \%)$ & \\
\hline & Severe addiction & $35(18.9 \%)$ & $15(10.6 \%)$ & $50(15.3 \%)$ & \\
\hline
\end{tabular}

of smartphone use, time spent on social media, chatting with friends, watching YouTube videos, and playing online/ offline games per day shown in Table 1. 43.3\% participants reported neck pain, $42.9 \%$ shoulder pain and $27.9 \%$ reported pain on their elbow while prolonged smartphone use. Pain intensity at the neck, shoulder, and elbow are presented in Table 2. The percentage of hand pain experienced in the last week is presented in Table 2 and a hand map diagram of six shaded area of the hand in shown in Fig. 1. The mean values of SAS, NDI, SPDI, 
Table 2 Pain experience in neck, shoulder, elbow and shaded area of hand $(n=326)$

\begin{tabular}{|c|c|c|c|c|c|c|}
\hline \multicolumn{3}{|l|}{ Variables } & \multirow{2}{*}{$\begin{array}{l}\text { Bangladeshi } \\
108(58.4 \%)\end{array}$} & \multirow{2}{*}{$\begin{array}{l}\text { Indian } \\
77(54.6 \%)\end{array}$} & \multirow{2}{*}{$\begin{array}{l}\text { Total } \\
185(56.7 \%)\end{array}$} & \multirow{2}{*}{$\begin{array}{l}P \text { value } \\
0.953\end{array}$} \\
\hline Neck pain & & No pain & & & & \\
\hline & & Very mild pain & $37(20.0 \%)$ & $43(30.5 \%)$ & $80(24.5 \%)$ & \\
\hline & & Moderate pain & $20(10.8 \%)$ & $13(9.2 \%)$ & $33(10.1 \%)$ & \\
\hline & & Fairly severe pain & $7(3.8 \%)$ & $3(3.1 \%)$ & $10(3.1 \%)$ & \\
\hline & & Very severe pain & $8(4.3 \%)$ & $5(3.5 \%)$ & $13(4.0 \%)$ & \\
\hline & & Worst pain & $5(2.7 \%)$ & $0(0 \%)$ & $5(1.5 \%)$ & \\
\hline \multirow{4}{*}{\multicolumn{2}{|c|}{ Shoulder pain }} & No pain & $100(54.15)$ & $86(61.0 \%)$ & $186(57.1 \%)$ & 0.209 \\
\hline & & Mild pain & 67 (36.2\%) & $44(31.2 \%)$ & $111(34.0 \%)$ & \\
\hline & & Moderate pain & $13(7.0 \%)$ & $8(5.7 \%)$ & $21(6.4 \%)$ & \\
\hline & & Severe pain & $5(2.7 \%)$ & $3(2.1 \%)$ & $8(2.5 \%)$ & \\
\hline \multirow{5}{*}{\multicolumn{2}{|c|}{ Elbow pain }} & No pain & $127(68.6 \%)$ & $108(76.6 \%)$ & $235(72.1 \%)$ & 0.106 \\
\hline & & Mild pain & $43(23.2 \%)$ & $25(17.7 \%)$ & 68 ()20.9\% & \\
\hline & & Moderate pain & $6(3.2 \%)$ & $5(3.5 \%)$ & $11(3.4 \%)$ & \\
\hline & & Severe pain & $6(1.6 \%)$ & $3(2.1 \%)$ & $9(2.8 \%)$ & \\
\hline & & Unbearable pain & $3(1.6 \%)$ & $0(0 \%)$ & $3(0.9 \%)$ & \\
\hline \multirow[t]{30}{*}{ Hand pain } & Area A & Never & $131(70.8 \%)$ & $118(83.7 \%)$ & 249 (76.4\%) & 0.007 \\
\hline & & 1-2 times last week & $37(20.0 \%)$ & $17(12.1 \%)$ & $54(16.6 \%)$ & \\
\hline & & 3-4 times last week & $11(5.9 \%)$ & $2(1.4 \%)$ & $13(4.0 \%)$ & \\
\hline & & Once every day & $5(2.7 \%)$ & $2(1.4 \%)$ & $7(2.1 \%)$ & \\
\hline & & Several times every day & $1(0.5 \%)$ & $2(1.4 \%)$ & $3(0.9 \%)$ & \\
\hline & Area B & Never & $125(67.6 \%)$ & $106(75.2 \%)$ & $231(70.9 \%)$ & 0.098 \\
\hline & & 1-2 times last week & 35 (18.9\%) & $24(17.0 \%)$ & $59(18.1 \%)$ & \\
\hline & & 3-4 times last week & $18(9.7 \%)$ & $9(6.4 \%)$ & $27(8.3 \%)$ & \\
\hline & & Once every day & $3(1.6 \%)$ & $1(0.7 \%)$ & $4(1.2 \%)$ & \\
\hline & & Several times every day & $4(2.2 \%)$ & $1(0.7 \%)$ & $6(1.5 \%)$ & \\
\hline & Area C & Never & $106(57.3 \%)$ & $105(74.5 \%)$ & $221(64.7 \%)$ & 0.001 \\
\hline & & 1-2 times last week & $47(25.4 \%)$ & $26(18.4 \%)$ & $73(22.4 \%)$ & \\
\hline & & 3-4 times last week & $17(9.2 \%)$ & $5(3.5 \%)$ & $22(6.7 \%)$ & \\
\hline & & Once every day & $10(5.4 \%)$ & $3(2.1 \%)$ & $13(4.0 \%)$ & \\
\hline & & Several times every day & $5(2.7 \%)$ & $2(1.4 \%)$ & $7(2.1 \%)$ & \\
\hline & Area D & Never & $130(70.3 \%)$ & 119 (84.4\%) & 249 (76.4\%) & 0.002 \\
\hline & & 1-2 times last week & $33(17.8 \%)$ & $18(12.8 \%)$ & $51(15.6 \%)$ & \\
\hline & & 3-4 times last week & $10(5.4 \%)$ & $2(1.4 \%)$ & $12(3.7 \%)$ & \\
\hline & & Once every day & $11(5.9 \%)$ & $1(0.7 \%)$ & $12(3.7 \%)$ & \\
\hline & & Several times every day & $1(0.5 \%)$ & $1(0.7 \%)$ & $2(0.6 \%)$ & \\
\hline & Area E & Never & $104(56.2 \%)$ & $99(70.2 \%)$ & $203(62.3 \%)$ & 0.005 \\
\hline & & 1-2 times last week & $50(27.0 \%)$ & $31(22.0 \%)$ & $81(24.8 \%)$ & \\
\hline & & 3-4 times last week & $20(10.8 \%)$ & $9(6.4 \%)$ & $29(8.9 \%)$ & \\
\hline & & Once every day & $10(5.4 \%)$ & $1(0.7 \%)$ & $11(3.4 \%)$ & \\
\hline & & Several times every day & $1(0.5 \%)$ & $1(0.7 \%)$ & $2(0.6 \%)$ & \\
\hline & Area F & Never & $117(63.2 \%)$ & $113(80.1 \%)$ & $230(70.6 \%)$ & 0.001 \\
\hline & & 1-2 times last week & $38(20.5 \%)$ & $19(13.5 \%)$ & $57(17.5 \%)$ & \\
\hline & & 3-4 times last week & $18(9.7 \%)$ & $5(3.5 \%)$ & $23(7.1 \%)$ & \\
\hline & & Once every day & $6(3.2 \%)$ & $3(2.1 \%)$ & $9(2.8 \%)$ & \\
\hline & & Several times every day & $6(3.2 \%)$ & $1(0.7 \%)$ & $7(2.1 \%)$ & \\
\hline
\end{tabular}




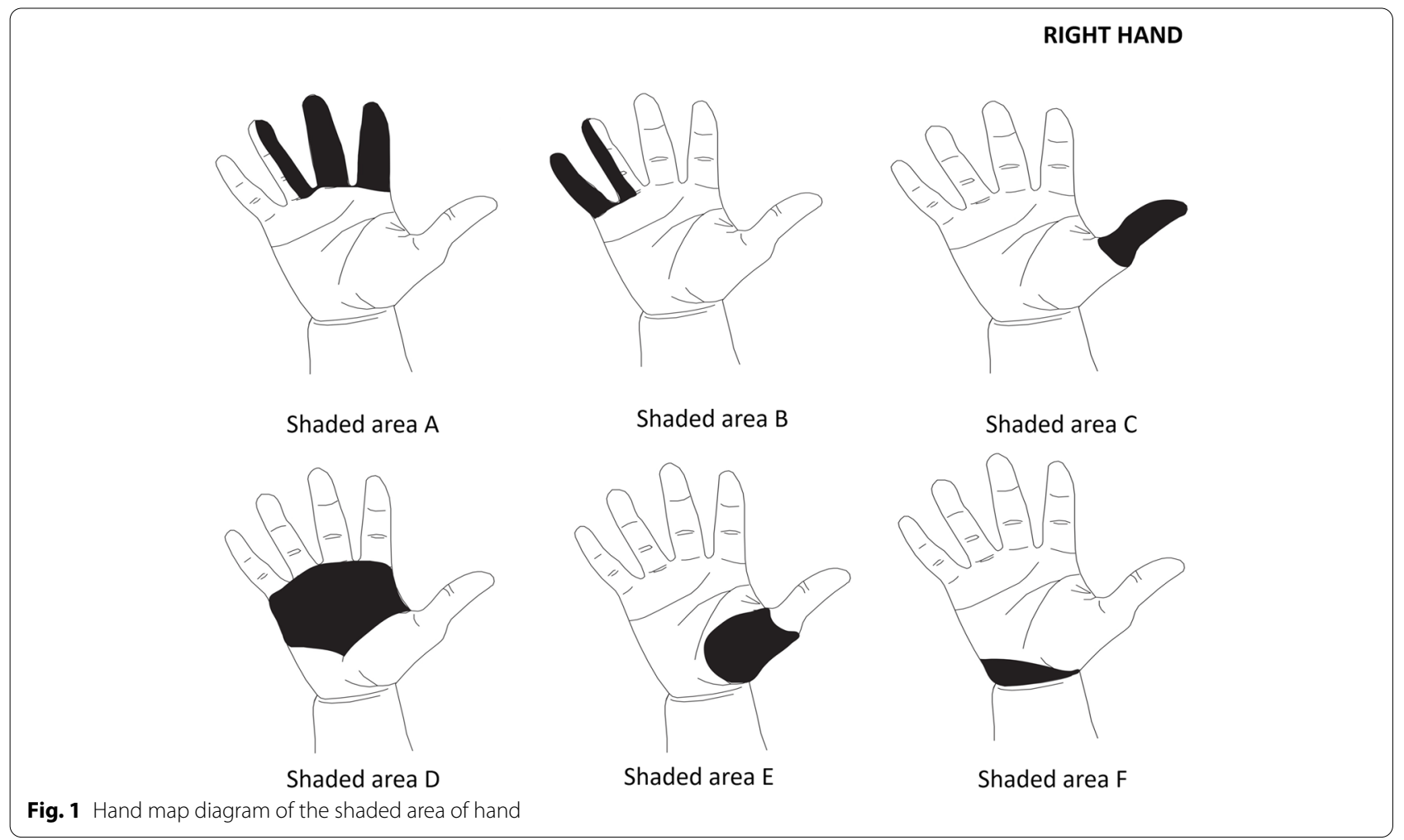

OES, and CHDQ score with 95\% confidential intervals were 33.56 (32.40-34.71), 9.34 (8.49-10.18), 7.26 (5.93-8.58), 16.51 (15.71-17.31), and 19.75 (17.17-22.33) respectively. There was significant difference in NDI $(p=$ $0.047)$, SPDI $(p=0.005)$, OES $(p=0.002)$, and CHDQ $(p=<0.001)$ among Bangladeshi and Indian population. The SAS has a significant association with NDI; $p<0.001$, SPDI; $p<0.001$, OES; $p<0.001$, and CHDQ; $p<0.001$. The association between SAS with NDI, SPDI, OES, and CHDQ are presented in Table 3.

\section{Discussion}

This cross-sectional study was conducted among Physiotherapy students from selected universities within Bangladesh and India. A face-to-face interview was conducted by sharing a web link of the questionnaire for gathering information. Three hundred twenty-six participants; both male and female have participated in this study. Among the study population, $46.3 \%$ were moderately addicted and $15.3 \%$ were severely addicted to their smartphones. There was a significant difference between level of smartphone addiction $(p=<0.001)$ among Bangladeshi and Indian populations that proves our alternative hypothesis.

In this present study, the prevalence rate of musculoskeletal pain in the neck, shoulder, and elbow is $43.3 \%$, $42.9 \%$, and $27.9 \%$ respectively. The prevalence rate of hand pain in the shaded area are A, B, C, D, E, and F is $23.6 \%, 29.1 \%, 35.3 \%, 23.6 \%, 37.7 \%$, and $29.4 \%$ respectively. There was no significant difference between the prevalence of pain in neck, shoulder, and elbow among Bangladeshi and Indian participants. Significant

Table 3 Association between smartphone addiction and neck, shoulder, elbow, and hand pain

\begin{tabular}{|c|c|c|c|c|c|c|}
\hline \multirow[t]{2}{*}{ Variables } & \multicolumn{2}{|c|}{ Bangladeshi } & \multicolumn{2}{|l|}{ Indian } & \multicolumn{2}{|l|}{ Overall } \\
\hline & $x^{2}$ value & $P$ value & $x^{2}$ value & $P$ value & $x^{2}$ value & $P$ value \\
\hline NDI & 28.009 & 0.005 & 37.408 & $<0.001$ & 47.090 & $<0.001$ \\
\hline SPAID & 28.497 & 0.005 & 21.502 & 0.011 & 38.047 & $<0.001$ \\
\hline OES & 24.863 & 0.015 & 24.870 & 0.003 & 42.361 & $<0.001$ \\
\hline CHDQ & 15.815 & 0.001 & 4.392 & 0.222 & 20.227 & $<0.001$ \\
\hline
\end{tabular}


difference was observed in hand pain within the shaded area, which is represented in Table 2. Smartphone addiction is significantly associated with NDI $(p=<$ $0.001)$, SPADI $(p=<0.001)$, OES $(p=<0.001)$, and CHDQ $(p=<0.001)$.

While using a smartphone, the head leans forward towards the mobile screen, which leads to poor posture which may develops chronic neck pain [19]. The physical exposure while using a smartphone requires neck flexion, shoulder flexion and abduction, elbow flexion, wrist and finger flexion and repetitive thumb movements for typing. Disability of neck, shoulder, elbow and hand among mobile-phone users might be due to the recurrent neck flexion posture, and overuse of shoulder and hand musculature. The prolonged use of smartphone for an prolonged period of time could lead to upper back pain [19], neck and shoulder pain [20], musculoskeletal pain in upper limb [21], neck and hand pain [5], and musculoskeletal pain in neck, shoulder, and hand [10] which is in-line with the results of this present study.

In this current study, the prevalence of neck pain among smartphone users is about $43.3 \%$. Al Abdulwahab et al. reported that smartphone addiction can lead to a poor posture causing significant disability to the neck. Continuous smartphone usage can lead to the development of faulty posture such as forward head neck which can produce injuries to the cervical spine and cause cervical pain $[1,22]$. A study conducted by Mustafaoglu $R$ et al. reported that $65.9 \%$ of young population who were addicted in smartphone had pain in their neck [3].

Shoulder pain and disability is associated with smartphone addiction reported by previous study. Mustafaoglu $\mathrm{R}$ et al. reported that $65.6 \%$ population have pain in their shoulder [3]. While using smartphone, muscle action is increased and pain pressure threshold is decreased which is associated with the increase of muscle fatigue. The repetitive movement while smartphone use causes constant muscle contraction which may give rise to microscopic injury to the muscle leading to develop musculoskeletal disorder [23].

In this present study the prevalence rate of hand pain in various shaded areas was reported to be $23.6-37.7 \%$. During smartphone use, sustained gripping, wrist flexion and ulnar deviation, and repetitive thumb movement are the main key factors that might be the leading cause of associated symptoms. During texting, repetitive adduction movement and high force are required on the key pad of the device to type. Long duration use of smartphone could adversely affect the musculoskeletal structure of hand [24]. S. Ahmed et al. reported that 29.2\% physiotherapy students had pain in their thumb due to extended smartphone use [5]. While text messaging in static position for prolonged period of time, requires overuse of the muscles of the hand leading to pain in the hand muscles [25].

In this current study, smartphone addiction is significantly associated with NDI, SPADI, OES, and CHDQ. The result of this study is in-line with the objective of the previous study reported by literatures. Musculoskeletal pain prevalence and smartphone addiction is significantly associated with one another reported by Mustafaoglu R et al. [23]. Text neck syndrome and short message service (SMS) thumb were significantly associated with nomophobia among physiotherapy students [5].

The musculoskeletal injuries are due to repetitive stress injuries that would have been prevented by taking some precautionary measures and controlled use of smartphone. Simple lifestyle changes for example, maintaining correct posture and avoid long term smartphone usage can prevent those symptoms. An interval of $20 \mathrm{~min}$ after using a smartphone for a prolonged period of time is required to avoid the negative effects and development of pain. The various biases of this study were eliminated by using the subsequent strategies. Random sampling methods was used to eliminate selection bias and nonresponse bias. The strength of this study was cost-effective, echo friendly (used Google form to collect data), and minimally time-consuming. However, we have a limitation as well, we conducted the study only in two centres in two countries that might not be the representative of whole nation. In the future, nationwide cohort study can be done to find the best results. This would prove useful for the young generations' smartphone users in making them aware about the ascending rise of harmful consequences of smartphone addiction and the long-term use.

\section{Conclusion}

The outcome of this current study reported that smartphone addiction negatively impacted the pain in the muscles of the neck, shoulder, elbow, and the hand. The negative impact of prolonged smartphone use has shown an association between smartphone addiction and musculoskeletal pain in different areas of the body. Caution should be taken towards the safe implementation of smartphone use.

\section{Acknowledgements}

We thank Dr. Amena Abdul Muthlib, BPT, Junior Physiotherapist, Mount Adora Hospital, Akhalia, Sylhet-3100, Bangladesh, for the final proof reading and technical support for preparation of the manuscript.

\section{Authors' contributions}

Sohel Ahmed conceived and designed the experiments, performed the experiments, analyzed and interpreted the data, and wrote the paper. Arushi Mishra conceived and designed the experiments and wrote the paper. Rahemun Akter conceived, designed, and performed the experiments. Asima Akter Sadia conceived, designed, and performed the experiments. Md. Hasanuzzaman 
Shah contributed reagents, materials, analysis tools or data, and performed the experiments. All authors read and approved the final manuscript.

\section{Funding}

This research did not receive any specific grant from funding agencies in the public, commercial, or non-profit sectors.

\section{Availability of data and materials}

Data will be made available on request.

\section{Declarations}

\section{Ethics approval and consent to participate}

Ethical approval has been obtained from the institutional ethical review board of Mount Adora hospital, Akhalia, Sylhet, Bangladesh. A digital consent was obtained from each participant after briefly describing the nature and purpose of the study.

\section{Competing interests}

The authors declare that they have no competing interests.

\section{Author details}

${ }^{1}$ Mount Adora Physiotherapy \& Neurorehabilitation, Center, Mount Adora Hospital, Akhalia-3100, Sylhet, Bangladesh. ²Department of Physiotherapy, Maharishi Markandeshwar Medical College and Hospital, Kumarhatti, Solan, Himachal Pradesh 173229, India. ${ }^{3}$ TB Project, Bangladesh Knitwear Manufacturers and Exporters Association, Fatullah, Narayanganj 1400, Bangladesh.

${ }^{4}$ Sher-E-Bangla Medical College, Barisal, Bangladesh.

Received: 2 November 2021 Accepted: 17 December 2021

Published online: 09 February 2022

\section{References}

1. AlAbdulwahab SS, Kachanathu SJ, AIMotairi MS. Smartphone use addiction can cause neck disability. Musculoskeletal Care. 2017;15:10-2. https://doi.org/10.1002/msc.1170.

2. Samaha M, Hawi NS. Relationships among smartphone addiction, stress, academic performance, and satisfaction with life. Comput Human Behav. 2016;57:321-5. Available from: doi.org/. https://doi.org/10.1016/j.chb. 2015.12.045.

3. Mustafaoglu R, Yasaci Z, Zirek E, Griffiths MD, Ozdincler AR. The relationship between smartphone addiction and musculoskeletal pain prevalence among young population: a cross-sectional study. Korean J Pain. 2021;34:72-81. Available from: doi.org/. https://doi.org/10.3344/kjp.2021. 34.1.72.

4. Chen B, Liu F, Ding S, Ying X, Wang L, Wen Y. Gender differences in factors associated with smartphone addiction: a cross-sectional study among medical college students. BMC Psychiatry. 2017;17:1-9. Available from: doi.org/. https://doi.org/10.1186/s12888-017-1503-z.

5. Ahmed S, Akter R, Pokhrel N, Samuel AJ. Prevalence of text neck syndrome and SMS thumb among smartphone users in college-going students: a cross-sectional survey study. J Public Heal. 2021;29:411-6. Available from: doi.org/. https://doi.org/10.1007/s10389-019-01139-4.

6. Baabdullah A, Bokhary D, Kabli Y, Saggaf O, Daiwali M, Hamdi A. The association between smartphone addiction and thumb/wrist pain: a cross-sectional study. Medicine (Baltimore). 2020;99:e19124. Available from: doi.org/https://doi.org/10.1097/MD.0000000000019124

7. Can S, Karaca A. Determination of musculoskeletal system pain, physical activity intensity, and prolonged sitting of university students using smartphone. Biomed Hum Kinet. 2019;11:28-35. Available from: doi. org/https://doi.org/10.2478/bhk-2019-0004

8. Matar Boumosleh J, Jaalouk D. Depression, anxiety, and smartphone addiction in university students- a cross sectional study. PLoS One. 2017;12:e0182239. Available from: doi.org/https://doi.org/10.1371/journ al.pone.0182239

9. Bian M, Leung L. Linking loneliness, shyness, smartphone addiction symptoms, and patterns of smartphone use to social capital. Soc Sci
Comput Rev. 2014;33:61-79. Available from: doi.org/https://doi.org/10. $1177 / 0894439314528779$

10. Ahmed S. Nikita pokhrel, Swastik Roy AJS. Impact of nomophobia: a nondrug addiction among students of physiotherapy course using an online cross-sectional survey. Indian J Psychiatry. 2019;61:77-80. Available from. https://doi.org/10.4103/psychiatry.IndianJPsychiatry.

11. Soliman Elserty N, Ahmed Helmy N, Mohmed Mounir K. Smartphone addiction and its relation to musculoskeletal pain in Egyptian physical therapy students. Eur J Physiother. 2020;22:70-8. Available from: doi. org/https://doi.org/10.1080/21679169.2018.1546337

12. Alzaid AN, Alshadoukhi $O$, Alnasian A. The prevalence of neck pain and the relationship between prolonged use of electronic devices and neck pain in a Saudi Arabia : Cross - Sectional Study in Saudi Arabia. Egypt J Hosp Med. 2018;70:1992-9. Available from: doi: https://doi.org/10.21608/ EJHM.2018.9405

13. Kwon M, Kim D-J, Cho H, Yang S. The smartphone addiction scale: development and validation of a short version for adolescents. PLoS One. 2013;8:e83558-e83558. Available from. https://doi.org/10.1371/journal. pone.0083558.

14. Vernon H, Mior S. The Neck Disability Index: a study of reliability and validity. J Manipulative Physiol Ther. 1991;14:409-15.

15. Roy J-S, MacDermid JC, Woodhouse LJ. Measuring shoulder function: a systematic review of four questionnaires. Arthritis Rheum. 2009;61:62332. Available from. https://doi.org/10.1002/art.24396.

16. Roach KE, Budiman-Mak E, Songsiridej N, Lertratanakul Y. Development of a shoulder pain and disability index. Arthritis Care Res. 1991;4:143-9.

17. Ebrahimzadeh MH, Kachooei AR, Vahedi E, Moradi A, Mashayekhi Z, Hallaj-Moghaddam M, et al. Validity and Cross-Cultural Adaptation of the Persian Version of the Oxford Elbow Score. Int J Rheumatol. 2014;2014:381237. Available from: doi.org/https://doi.org/10.1155/2014/ 381237

18. Erdinc O, Hot K, Ozkaya M. Turkish version of the Cornell Musculoskeletal Discomfort Questionnaire: cross-cultural adaptation and validation. Work. 2011 [cited 2019 Apr 18];39:251-60. Available from: doi: https://doi.org/ 10.3233/WOR-2011-1173.

19. Neupane S, Ali U MA. Text Neck Syndrome - Systematic Review. Imp J Interdiscip Res. 2017;3:141-148. Available from: doi: https://doi.org/10. 1016/s0003-6870(02)00036-4

20. Kim H-J, Kim J-S. The relationship between smartphone use and subjective musculoskeletal symptoms and university students. J Phys Ther Sci. 2015;27:575-9. Available from: doi:. https://doi.org/10.1589/jpts.27.575.

21. Sharan D, Mohandoss M, Ranganathan R, Jose J. Musculoskeletal disorders of the upper extremities due to extensive usage of hand held devices. Ann Occup Environ Med. 2014;26:22. Available from: doi: https:// doi.org/10.1186/s40557-014-0022-3.

22. Bonney RA, Corlett EN. Head posture and loading of the cervical spine. Appl Ergon. 2002;33:415-417. Available from: doi: https://doi.org/10. 1016/s0003-6870(02)00036-4

23. Eitivipart AC, Viriyarojanakul S, Redhead L. Musculoskeletal disorder and pain associated with smartphone use: a systematic review of biomechanical evidence. Hong Kong Physiother J. 2018;38:77-90. Available from: doi.org/. https://doi.org/10.1142/S1013702518300010.

24. Sharan D, Ajeesh PS. Risk factors and clinical features of text message injuries. Work. 2012;41 Suppl 1:1145-1148. Available from: doi: https://doi. org/10.3233/WOR-2012-0294-1145.

25. Shah PP, Sheth MS. Correlation of smartphone use addiction with text neck syndrome and SMS thumb in physiotherapy students. Int J Community Med Public Heal. 2018;5:2512-6. Available from: doi. https://doi. org/10.3233/WOR-2012-0294-1145.

\section{Publisher's Note}

Springer Nature remains neutral with regard to jurisdictional claims in published maps and institutional affiliations. 